\title{
The use of nuclear data in the field of nuclear fuel recycling
}

\author{
Julie-Fiona Martin ${ }^{1, a}$, Agnès Launay ${ }^{2}$, Gabriele Grassi ${ }^{1}$, Christophe Binet ${ }^{2}$, Jacques Lelandais ${ }^{2}$, and Erick Lecampion ${ }^{2}$ \\ 1 AREVA NC La Défense, 1 place Jean Millier, 92084 Paris La Défense, France \\ 2 AREVA NC La Hague, 50440 Beaumont-Hague, France
}

\begin{abstract}
AREVA NC La Hague facility is the first step of the nuclear fuel recycling process implemented in France. The processing of the used fuel is governed by high standards of criticality-safety, and strong expectations on the quality of end-products. From the received used fuel assemblies, the plutonium and the uranium are extracted for further energy production purposes within the years following the reprocessing. Furthermore, the ultimate waste - fission products and minor actinides on the one hand, and hulls and endpieces on the other hand - is adequately packaged for long term disposal. The used fuel is therefore separated into very different materials, and time scales which come into account may be longer than in some other nuclear fields of activity. Given the variety of the handled nuclear materials, as well as the time scales at stake, the importance given to some radionuclides, and hence to the associated nuclear data, can also be specific to the AREVA NC La Hague plant. A study has thus been led to identify a list of the most important radionuclides for the AREVA NC La Hague plant applications, relying on the running constraints of the facility, and the endproducts expectations. The activities at the AREVA NC La Hague plant are presented, and the methodology to extract the most important radionuclides for the reprocessing process is detailed.
\end{abstract}

\section{Introduction}

This paper aims at presenting the activities of AREVA NC La Hague facility, which is the first step of the nuclear fuel recycling process in France. The specificities of these activities will be underlined, in order to explain how the process at stake accounts for a particular interest in some radionuclides, and consequently in the related nuclear data. The methodology to identify the top-list of the radionuclides of interest is presented, and two main reasons for the AREVA NC La Hague process specificities, namely the specific materials yielded by the separation process of the fuel assembly, and the time scales, will be developed.

First, the plant and its role within the French nuclear fuel cycle are introduced in Sect. 2. Then, the specificities of the process are underlined in Sect. 3, leading to understand the higher interest for some particular radionuclides. This brings the opportunity to build a list of radionuclides that are of particular interest to the AREVA NC La Hague plant, and the methodology that has been implemented at AREVA NC La Hague to draw this list is explained. Examples are given in Sect. 4.

\section{AREVA NC La Hague plant, and the reprocessing of used fuels}

\subsection{Nuclear fuel cycle in France}

Two steps for the recycling of used fuels

France is equipped with 58 Pressurized Water Reactors, providing most of the country's electricity. The used fuel is reprocessed and recycled for further use in nuclear

a e-mail: julie-fiona.martin@areva.com energy production. This also allows to minimize both the amount and radiotoxicity of final waste resulting from fuel assemblies. About one third of French reactors can be fueled with new assemblies made from recycling [1]. The recycling of the used fuel is separated in two steps:

1. the separation of valuable materials: $\mathrm{Pu}$ and $\mathrm{U}$

2. the fabrication of new fuel assemblies from these materials.

AREVA NC La Hague is in charge of separating the Pu and $\mathrm{U}$, which are then sent to other facilities for the fabrication of new fuel assemblies, and of the conditioning of ultimate waste (fission products and minor actinides on the one hand, and hulls and end-pieces on the other hand) for long term disposal.

\section{Processing capabilities of AREVA NC La Hague - facts and figures}

Both French and foreign assemblies can be processed at AREVA NC La Hague. The following list gives an excerpt of fuel types that have been, or are planned to be, processed:

- Pressurized Water Reactors, UOx, MOx, and ERU (UOx made from recycled U)

- Boiling Water Reactors, both UOx and MOx

- UNGG (Uranium Naturel Graphite Gaz)

- Research reactors, either French or foreigner

- Fast Reactors.

The associated range of total burnup and initial enrichment is also wide: up to $62 \mathrm{GWd} / \mathrm{tHM}$ (gigawatt day per ton heavy metal) for an initial enrichment of $4.55 \%$ for light water reactors, and up to $700 \mathrm{GWd} / \mathrm{tHM}$ for an initial enrichment around $20 \%$ or $95 \%$ for research reactors. The

(C) The Authors, published by EDP Sciences. This is an Open Access article distributed under the terms of the Creative Commons Attribution License 4.0 (http://creativecommons.org/licenses/by/4.0/). 
fuel assemblies are first cooled in the reactors interim storage pools for at least six months before being sent to AREVA NC La Hague. The processing takes place within the following years.

\subsection{The reprocessing process}

At the AREVA NC La Hague facility, the used fuel is separated into four end-products:

1. Plutonium, as plutonium oxide

2. Depleted uranium, as uranyle nitrate

3. Fission products and minor actinides, conditioned in standard vitrified waste containers (CSD-V)

4. Metallic structures, conditioned in standard compacted waste containers (CSD-C).

A scheme of the process is given in Fig. 1, and it is hereunder unfolded [2]:

- Pools: upon reception, the assembly is stored in interim storage pools until it is reprocessed.

- Controlling and feeding: once the processing is scheduled, the assembly is first scanned for a burnup measurement which is used for criticality-safety purposes; the measured value is compared to the value provided by the reactor. The assembly is then fed to the shearing room.

- Shearing: the shearing consists in cutting the assembly into small pieces which will then be dissolved. The endpieces are cut and sent directly for rinsing, while the hulls are sent to the rotary dissolver.

- Gas treatment: the shearing of the assembly breaks up what used to be the first barrier of the fuel assembly. This causes the release of gases, which are treated and filtered.

- Dissolving: the hulls containing the used fuel are sent to the rotary dissolver, which will permit to plunge them into an acid bath. The fuel is dissolved, leaving the hulls intact. The hulls are then rinsed and sent with the endpieces.

- Compacting: end-pieces and hulls are compacted into a standard container named CSD-C for Conteneur Standard de Déchets Compactés (Standard Compacted Waste Container).

- Fission products and minor actinides separation: the second separation step permits to separate the fission products and minor actinides on the one hand, from the uranium and plutonium on the other hand.

- Assessment tanks: both these solutions are measured in assessment tanks for further processing.

- Vitrification: the resulting solution of fission products and minor actinides is incorporated into glass and melt into a standard container named CSD-V for Conteneur Standard de Déchets Vitrifiés (Standard Vitrified Waste Container).

- U/Pu separation: the PUREX process permits to separate uranium from plutonium.

- Uranyle nitrate: the uranium is treated into uranyle nitrate for transportation to further facilities which will allow its re-use in reactor cores.

- Plutonium oxide: the plutonium is treated into oxide powder for transportation to further facilities which will allow its re-use in reactor cores.

From the input - used fuel assemblies - to the outputs plutonium, reprocessed uranium, CSD-C and CSD-V - the variety of materials handled at AREVA NC La Hague plant is substantial; all the more since all the intermediary steps represent intermediary mixture such as $\mathrm{U}+\mathrm{Pu}$ solution, fission products and minor actinides solutions, etc.

\subsection{Quantities driving the facility}

The quantities driving the process mainly pursue a twofold goal that is the (criticality-)safety to which we also attribute the matters of radioprotection on the one hand, and the quality of end-products on the other hand. These quantities are summarized here-under, according to the goal they are associated to:

1. Criticality-safety and radioprotection

- decay heat, specific thermal power

- criticality

- radioactivity of all materials $(\alpha, \beta, \gamma$ and $\mathrm{n}$ emission)

- gaseous emissions from the plant

2. Quality of end-products

- energy potential of plutonium and reprocessed uranium for recycling

- final waste packages quality for long term storage.

The radionuclides of interest for AREVA NC La Hague plant are related to all these quantities, that are calculated and/or monitored on-line.

\section{Calculation}

The calculation tools used at La Hague, a depletion code and a post-processing tool, both rely on the JEFF-3.1.1. library [3]. In order to have a good understanding of the precision of the calculations, it is paramount that the involved nuclear data be well-mastered, both in terms of value and in associated uncertainty. Furthermore, one should keep in mind the fact that the inventory calculation of one radionuclide relies on the knowledge of the nuclear data associated to the full filiation chain that leads to that given radionuclide.

Although the physical quantities of interest (e.g. radiation emission, specific thermal power due to radioactive decay, etc.) are common to other fields of the nuclear industry, the reprocessing activities that take place at AREVA NC La Hague are specific in terms of handled materials due to the separation from the used fuel assembly, and time scales at stakes.

\section{Specificities of AREVA NC La Hague and methodology}

\subsection{Materials and time scales}

\section{Materials}

A specificity of the AREVA NC La Hague process stands in the variety of handled nuclear materials: indeed, from the received fuel assembly, materials will be separated to finally provide four end-products ( $\mathrm{U}, \mathrm{Pu}, \mathrm{CSD}-\mathrm{C}$ and CSD-V, cf. Sect. 2.2); and on top of that, the separation unfolds in many steps, which means that one can find transition mixtures, that also need to be dealt with.

For example, in a fuel assembly, one can find uranium isotopes ranging from ${ }^{232} \mathrm{U}$ to ${ }^{238} \mathrm{U}$. However, 


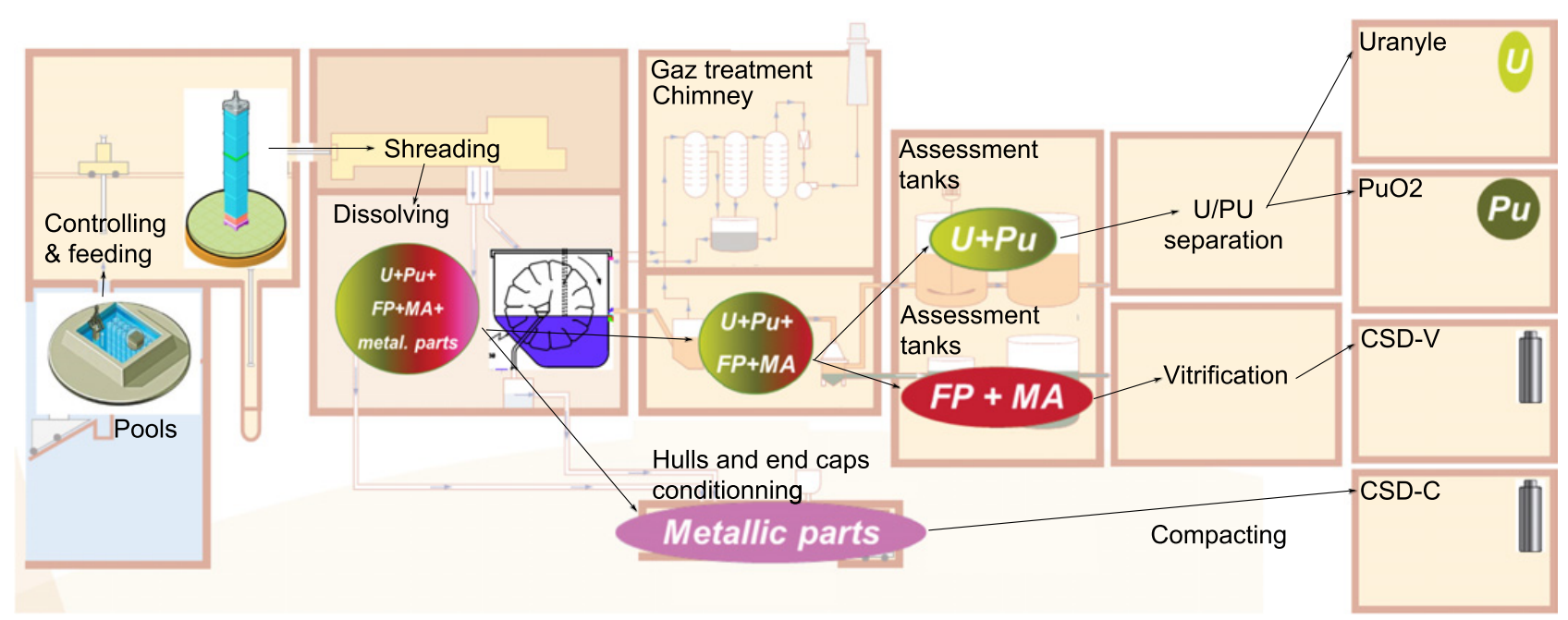

Figure 1. Scheme of the reprocessing process at AREVA NC La Hague plant.

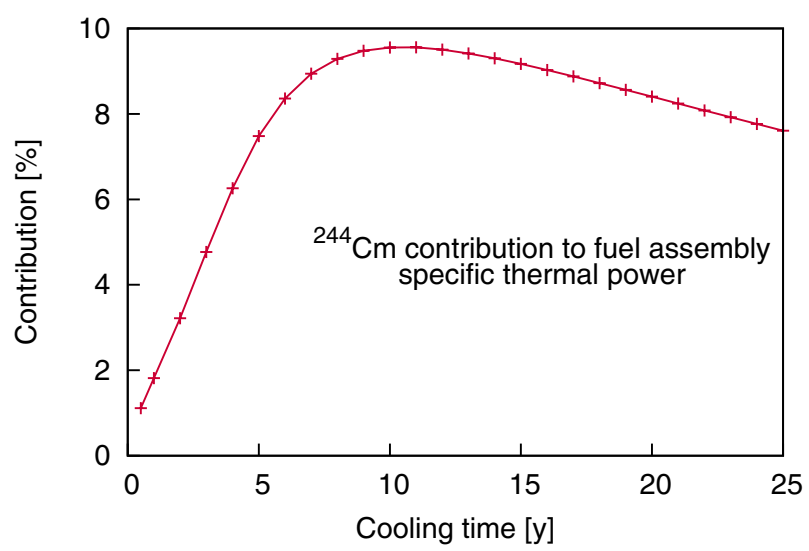

Figure 2. Contributions of ${ }^{244} \mathrm{Cm}$ to total assembly decay heat. PWR UOx, $e_{i}=3.7 \%$, total burnup $=45 \mathrm{GWd} / \mathrm{t}$.

light isotopes $\left({ }^{232-234} \mathrm{U}\right)$ are scarce, and they contribute little to the physical properties of the assembly, such as radioactivity etc. Yet, once the uranium is separated from the other components of the fuel, the relative contribution of the light isotopes becomes more important. Therefore, the expectations in terms of calculation precision for light uranium isotopes is more stringent for separated uranium than for the assembly.

\section{Time scales}

The AREVA NC La Hague plant manages longer time behaviour of the fuel assembly and its components, as compared to other nuclear energy activities such as reactor operation for example. Indeed, time scales range from a few years, before processing, up to some million years, regarding the final waste containers dedicated to long term storage. This accounts for a change in the inventory of the fuel and end-products, due to the decay of some radionuclides.

On the one hand, this means the process is not affected by short-lived radionuclideshandled materials due to the separation from the used fuel assembly, since most of them have disappeared before the used fuel is sent to AREVA NC La Hague. For example, all short lived radionuclide which contribute strongly to the decay heat at short time scales can be neglected. A

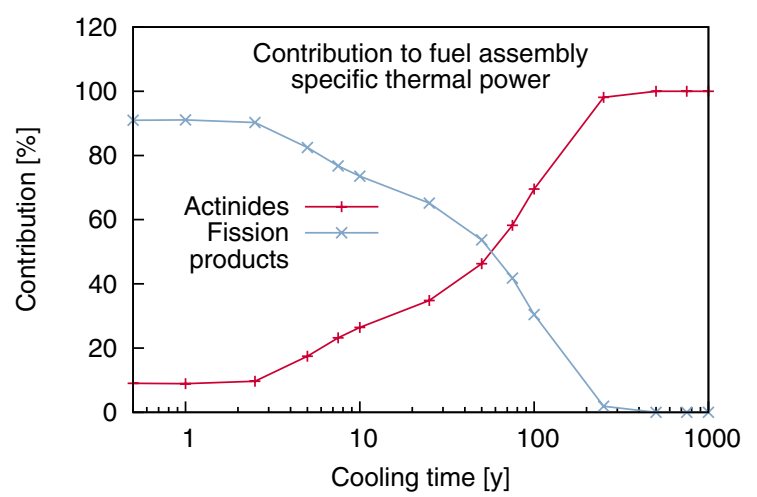

Figure 3. Respective contributions of $\mathrm{Pu}$, fission products and minor actinides to total assembly decay heat. PWR UOx, $\mathrm{e}_{i}=$ $3.7 \%$, total burnup $=45 \mathrm{GWd} / \mathrm{t}$.

study presented in 2014 on the calculation of the decay heat of full assemblies for cooling times ranging from 6 months to a few years shows that taking into account only 25 radionuclides permits to cover in excess of $98 \%$ of the total decay heat of the assembly, thus strongly simplifying the decay heat calculation [4].

On the other hand, longer-lived radionuclides which can be neglected for short-time decay heat will become prominent at longer cooling times. This is for example the case of ${ }^{244} \mathrm{Cm}$, as shown in Fig. 2: while its contribution is negligible at short-times, when short-lived fission products are prominent, it becomes more and more important until it reaches almost $10 \%$ of the total decay heat of the assembly after around ten years cooling time.

Figure 3 shows the respective contribution of plutonium, fission products and minor actinides to an assembly decay heat, on a wider period ranging from 6 months to ten thousand years cooling time. It underlines the fact that up to a cooling time of approximately 40 years, fission products play prominently on the total decay heat; however, beyond this limit, heavy nuclides take the leadership. It shows that depending on the time scale we are considering, the relative importance of some radionuclides contribution to a physical property of interest varies strongly. 


\section{Specificities}

It has been underlined that the AREVA NC La Hague plant handles a wide variety of materials and mixtures, and is involved in wide time-scales commitments. This results in an increased interest in a variety of radionuclides, that may not be as strong for other stakeholders of the nuclear industry. It has thus appeared important that the reprocessing activities be able to draw its top-list of radionuclides of interest, in order to steer the improvement efforts of the nuclear data community by sharing its point of view. The methodology implemented to build this toplist is presented in the following section.

\subsection{Methodology to extract the top-list of radionuclides of interest}

The previous sections have detailed the steps of the reprocessing process, and underlined the fact that quantities that drive the process are governed by specific radionuclides, that may not be of the same importance as to other fields of nuclear industry, therefore leading to the need to draw a top-list of radionuclides of interest. The methodology that was implemented to identify this top-list is the following:

1. first, the process has been segmented into as many steps as needed to take into account the facility equipment, the handled materials and the time scale involved

2. for each step, the physical properties that drive the process have been identified (whether related to criticality-safety demands, or quality expectations)

3. finally, for each of these physical properties, or quantities of interest, the involved radionuclides have been extracted.

This has led to an exhaustive list of radionuclides of interest. The respective contribution of each radionuclide to the considered physical property has then enabled us to prioritize and focus on a shorter list.

The following part will provide a few examples, declined according to the work-steps that are performed for each assembly ahead of, and during, the process: the preparation, the optimization and the on-line monitoring of the process.

\section{Radionuclides of interest: examples for the preparation, optimization and monitoring of the process}

In order to ensure the fulfilling of the previously mentioned goals (criticality-safety insurance, and quality of endproducts), the analysis work is organized in three steps:

1. the preparation of the process, ahead of reception of the fuel assemblies; it consists in anticipating the full process, the quality of end-products, the expected ease of processing

2. the optimization, ahead of the process, for one set of assemblies selected for processing; the optimization consists in sequencing the fuel assemblies in order to ensure the respect of criticality-safety related constraints, and the quality of end-products, while respecting all constraints of the facility.
3. the on-line monitoring of the process; the AREVA $\mathrm{NC}$ La Hague plant is equipped with many online measurement stations, for the control of the smoothrunning of the process [5]

These steps will be detailed hereafter, and will provide examples to the implemented methodology to identify the radionuclides of interest.

\subsection{Preparing the fuel reception}

Ahead of the reception of the fuel, its description in terms of technological design, initial enrichment, and full history including irradiation and cooling phases, are provided by the power plant. From such data, the inventory of the used fuel is calculated. This allows to anticipate the whole process procedure, identify potential adjustment in the process for this specific fuel, and simulate the resulting end-products, both in quantity and quality.

For example, potential adjustment may be a matter of fission products and minor actinides solution concentration in tanks ( $c f$. Fig. 1) that will be adjusted according to the solution specific heat, to ensure the respect of thermal limitations in tanks. Indeed, the fission products and minor actinides represent a minor contribution to the fuel assembly mass, yet they are responsible for most of its specific heat up to forty years after the last irradiation (cf. Fig. 3). Therefore, it is understood that the separated fission products and minor actinides present an even higher specific heat, and once separated, they must be handled adequately and their concentration in the tanks is of utmost importance to ensure the thermal limitations of the equipment are respected. The radionuclides that participate most in this decay heat will therefore be of high interest.

\subsection{Optimizing the process}

A set of assemblies is scheduled for processing, it then needs to be given an order of reprocessing that will permit a smooth running of the plant. For example, one may want to process alternatively warmer and colder assemblies so that they compensate with one another, and yield a reasonable mean specific thermal power. The resulting selection of the fuel assemblies for processing, as well as their order of reprocessing, are directives for the upcoming processing.

\subsection{Monitoring the reprocessing}

Many measurement stations pave the processing in order to provide a clear information on the running of the process, and monitor the quantities of interest (decay heat in tanks, etc.) on-line [5].

While some measurements provide the expected results directly, such as a thermometer providing the temperature in the tanks, others need post-processing to extract the final result.

It is the case, for example, for the burnup measurement which is performed right ahead of the shearing, in the feeding and controlling room (cf. Fig. 1). This burnup measurement is performed by means of $\gamma$ measurement stations, and the extracted ratio of ${ }^{137} \mathrm{Cs}$ to ${ }^{134} \mathrm{Cs}$ is a linear function of the burnup. In this example, specific radionuclides of interest are ${ }^{137} \mathrm{Cs}$ and ${ }^{134} \mathrm{Cs}$, because they act as measurement tracers in order to reach the assembly burnup from the measured $\gamma$-ray spectrum. 


\section{Top-list of radionuclides of interest, and perspectives}

AREVA NC La Hague has thus been able to identify a short-list of radionuclides of higher interest for its own activities; a few examples of such radionuclides $\left({ }^{244} \mathrm{Cm},{ }^{232-234} \mathrm{U},{ }^{134,137} \mathrm{Cs} . ..\right)$ have been presented in this paper.

In collaboration with AREVA NC, CEA has launched a study to identify potential opportunities to improve the precision of depletion calculation and association postprocessing, potentially via an evolution of the associated nuclear data, and focusing first on the radionuclides of the short-list [6].

\section{Conclusion}

This paper has presented the activities led at AREVA NC La Hague facility, which is the first step of the reprocessing of used fuel in the French nuclear fuel cycle. The detailed analysis of the process of this plant has highlighted two main vectors explaining its specificities: (1) the variety of nuclear materials that are handled, from the used fuel assembly as an input, to $\mathrm{Pu}$ and $\mathrm{U}$ for recycling, and final vitrified and compacted waste containers, as outputs; and (2) the wide time scales that are considered, from a few months after the last irradiation to the behaviour of final waste containers after a few million years.

It has appeared that these specificities result in an increased interest in some radionuclides, interest which may show stronger than in other fields of nuclear-related activity. AREVA NC La Hague has thus worked to build a short-list of these radionuclides: the implemented methodology relied on the analysis of the process itself, and the quantities governing it so as to ensure the respect of the stringent demands in terms of criticality-safety and radioprotection, and the high quality of the end-products. This methodology has been presented, and a few examples have been given in this paper.

\section{References}

[1] CEA. Les centrales nucléaires dans le monde. In ELECNUC. CEA, Gif sur Yvette, France (2015)

[2] M. Lecomte and B. Bonin. Traitement-recyclage du combustible nucléaire usé. In CEA Saclay, Groupe Moniteur (2008)

[3] A. Santamarina, D. Bernard, P. Blaise, M. Coste, A. Courcelle, T.D. Huynh, C Jouanne, P. Leconte, O Litaize, S Mengelle, et al. JEFF report 22(10.2) (2009)

[4] A. Launay, G. Grassi, E. Lecampion, J. Lelandais, R. Eschbach, and L. San Felice. A methodology for fast and accurate decay heat calculations for in-pool used fuel assemblies developed at areva la hague reprocessing facility. In PHYSOR (2014)

[5] C. Eleon, C. Passard, N. Hupont, N. Estre, O. Gueton, F. Brunner, G. Grassi, M. Batifol, P. Doumerc, T. Dupuy, B. Battel, and J.C. Vandamme. Status of the nuclear measurement stations for the process control of spent fuel reprocessing at areva nc la hague. In ANIMMA 4th edition, p. 1-5 (2015)

[6] A. Rizzo, C. Vaglio-Gaudard, J.-F. Martin, G. Noguère, and R. Eschbach. Work plan for improving the DARWIN2.3 depleted material balance calculation of nuclides of interest for the fuel cycle. In ND2016 - to be published (2016) 